Saoussen Dimassi

Frédéric Vargas

Aissam Lyazidi

Ferran Roche-Campo

Jean Dellamonica

Laurent Brochard

\section{Intrapulmonary percussive ventilation superimposed on spontaneous breathing: a physiological study in patients at risk for extubation failure}

Received: 13 September 2010

Accepted: 6 April 2011

Published online: 9 June 2011

(C) Copyright jointly held by Springer and ESICM 2011

Electronic supplementary material

The online version of this article (doi:10.1007/s00134-011-2249-6) contains supplementary material, which is available to authorized users.

S. Dimassi - F. Vargas - A. Lyazidi .

F. Roche-Campo · J. Dellamonica .

L. Brochard

Réanimation Médicale, AP-HP, Centre

Hospitalier Albert Chenevier-Henri

Mondor, Créteil, France

e-mail: saoussen.dimassi@hcuge.ch

S. Dimassi · L. Brochard ( $\bullet$ )

Soins-Intensifs, University Hospitals

of Geneva, 1211 Geneva 14,

Geneva, Switzerland

e-mail: laurent.brochard@hcuge.ch

\section{F. Vargas}

Département de Réanimation Médicale, Hôpital Pellegrin Tripode, Bordeaux, France

\section{F. Roche-Campo}

Servei de Medicina Intensiva,

Hospital de Sant Pau, Barcelona, Spain
J. Dellamonica

Réanimation Médicale, CHU de Nice, Hôpital L'Archet, Université de Nice Sophia Antipolis, Nice, France

L. Brochard

INSERM U955, Team 13,

Université Paris EST, Créteil, France

Abstract Purpose: Intrapulmonary percussive ventilation (IPV) is a high-frequency ventilation modality that can be superimposed on spontaneous breathing. IPV may diminish respiratory muscle loading and help to mobilize secretions. The aim of this prospective study was to assess the short-term effects of IPV in patients at high risk for extubation failure who were receiving preventive non-invasive ventilation (NIV) after extubation. Methods: Respiratory rate, work of breathing, and gas exchange were evaluated in 17 extubated patients during $20 \mathrm{~min}$ of IPV and 20 min of NIV delivered via a facial mask, separated by periods of spontaneous breathing. The pressuresupport level during NIV was adjusted until tidal volume reached $6-8 \mathrm{ml} / \mathrm{kg}$ and positive end-expiratory pressure (PEEP) $4-5 \mathrm{cmH}_{2} \mathrm{O}$. For IPV, the pressurisation frequency was set at 250 cycles/min and driving pressure at 1.2 bar. The pressure- time product of the diaphragm (PTPdi/min) was measured using an oesophageal and gastric doubleballoon catheter. Results: Transdiaphragmatic pressure and PTPdi/min improved significantly $(p<0.01)$, from a median [25th-75th percentiles] of 264 [190-300] to 192 [152-221] $\mathrm{cmH}_{2} \mathrm{O}$ s/min with IPV and from 273 [212-397] to 176 [120-216] $\mathrm{cmH}_{2} \mathrm{O}$ s/min with NIV. Respiratory rate decreased significantly from 23 [19-27] to 22 [17-24] breaths/min for IPV and from 25 [19-28] to 20 [18-22] breaths/min for NIV $(p<0.01)$. Mean $\mathrm{PaCO}_{2}$ decreased after NIV (from 46 [42-48] to 41 [36-42] mmHg, $p<0.01$ ) but not after IPV. There was no noticeable effect on oxygenation.

Conclusions: IPV is an interesting alternative to NIV in patients at risk for post-extubation respiratory failure. Both NIV and IPV diminished the respiratory rate and work of breathing, but IPV was less effective in improving alveolar ventilation.

Keywords Non-invasive ventilation . Respiratory monitoring .

Mechanical ventilation: weaning 


\section{Introduction}

Post-extubation respiratory failure is a major clinical problem in intensive care unit (ICU) patients. Approximately 10 to $20 \%$ of extubated patients may require reintubation [1] and the in-hospital mortality of these patients may reach 30-40\% [2, 3]. Experts at an international consensus conference described non-invasive ventilation (NIV) as holding promise for preventing reintubation after extubation failure [4]. Randomised trials $[5,6]$ have been performed to assess whether NIV prevented post-extubation failure in high-risk patients. Several studies that used comparable definitions of highrisk patients and similar study designs showed lower reintubation rates in the groups given preventive NIV compared to those given standard care. In a randomised controlled trial, preventive NIV diminished ICU and 90-day mortality rates in the subgroup of hypercapnic patients [7]. Thus, prompt initiation of a 48-h period of NIV in high-risk patients decreases the risk of postextubation respiratory failure.

Intrapulmonary percussive ventilation (IPV) delivers high-frequency mini-bursts of high-flow gas that are superimposed on the spontaneous breathing pattern. IPV may improve gas exchange and secretion clearance [8]. Percussion frequency, timing, and driving pressure must be adjusted, but no specific adaptation to the patient's breathing pattern is required [9]. IPV was first used by physiotherapists for secretion removal in patients with Duchenne muscular dystrophy [10], cystic fibrosis [11], or atelectasis [12]. This safe, intermittent, and simple technique has been shown to produce some degree of diaphragmatic unloading in patients with chronic obstructive pulmonary disease (COPD) who are stable or experiencing a mild exacerbation $[13,14]$. Compared to NIV, IPV is superimposed on spontaneous breathing during the whole respiratory cycle with no synchronisation required between the patient's own breathing.

The aim of this prospective study was to assess the short-term physiologic effects of an IPV session in patients at high-risk for extubation failure, comparatively to NIV.

\section{Materials and methods}

Patients

A prospective physiological study was conducted in the ICU of the Henri Mondor University Hospital, Créteil, France. The experimental protocol was approved by the appropriate ethics committee (Comité de Protection des Personnes IX Créteil) and informed consent was obtained from patients or next of kin.
Inclusion criteria

All patients who required orotracheal intubation for $48 \mathrm{~h}$ or longer and who tolerated a spontaneous breathing trial after recovery from their acute episode were considered eligible for the study if they had at least two of the following risk factors for post-extubation respiratory failure [5]: age older than 65 years, underlying heart or respiratory failure, and Acute Physiology and Chronic Health Evaluation (APACHE) II [15] score greater than 12 on the day of extubation. Tracheostomised patients were not screened for the study. In our ICU, post-extubation NIV is used in all patients having at least two of these three criteria.

Exclusion criteria were related to NIV and to the insertion of a double-balloon catheter: facial or cranial trauma or surgery, recent gastric or oesophageal surgery, active upper gastrointestinal bleeding, lack of cooperation, and a decision to limit treatment intensity in the ICU.

\section{Study design and measurements}

Patients meeting weaning criteria (see details in the "Electronic supplementary material", ESM) had a spontaneous breathing trial (T-piece or low-pressure support with no positive end-expiratory pressure, PEEP) once a day. When the trial was well tolerated, the patient was extubated and enrolled in the study. Before extubation, a double-balloon catheter was positioned to record oesophageal and gastric pressures.

Five study sessions were performed after extubation. Within $2 \mathrm{~h}$ after extubation, NIV and IPV were tested, in random order, via a face mask (Performatrak ${ }^{\circledR}$, Philips Respironics, Murrysville, PA, USA). The IPV and NIV sessions lasted $20 \mathrm{~min}$. The other three sessions were periods of spontaneous breathing before, between, and after the NIV and IPV sessions.

\section{Intrapulmonary percussive ventilation}

IPV is a high-frequency ventilation modality that delivers subphysiological tidal volumes at rates higher than $1 \mathrm{~Hz}$. The bursts are produced by a sliding venturi (the Phasitron $\left.{ }^{\circledR}\right)$ [21] powered by compressed gas whose pressure can be varied between 0.8 to 3.5 bar and that generates oscillations between 80 and 650 cycles/min. The venturi effect drags humidified gas from a nebuliser through the Phasitron ${ }^{\circledR}$ to the patient. A continuous positive pressure is maintained, while the high-velocity percussive inflow opens the airways and enhances intrabronchial secretion mobilization. We chose the $1.2 \mathrm{bar} / 250$ cycles $/ \mathrm{min}$ setting on the basis of previous results by Nava et al. [13]. 
In our study, IPV was delivered by a specific ventilator (IPV1-C ${ }^{\circledR}$ device, Percussionnaire Corporation, Sandpoint, ID, USA) (see Fig. S1 in the ESM) through a face mask. The pressurisation frequency was set at 250 cycles/ min and driving pressure at $1.2 \mathrm{bar}$. The inspiration/ expiration ratio of the oscillatory flow generated by the device (independent of the patient's breathing pattern) was set at $1 / 2.5$.

Humidification was provided via the nebuliser recommended by the IPV device manufacturer. The nebuliser was inserted in the circuit and $10 \mathrm{ml}$ of saline solution was delivered for humidification. The oxygen fraction was adjusted using a blender.

\section{Non-invasive ventilation}

All patients were ventilated using an ICU ventilator capable of providing NIV. The ventilator was set in pressure-support mode with PEEP. The pressure-support level was adjusted until tidal volume reached $6-8 \mathrm{ml} / \mathrm{kg}$. PEEP was set at 4 or $5 \mathrm{cmH}_{2} \mathrm{O}$. The inspiratory trigger was set between 1 and $3 \mathrm{l} / \mathrm{min}$, pressurisation slope at $80 \%$, and inspiratory-expiratory cycling at $25 \%$ of peak flow.

\section{Data collection and recordings}

The following variables were collected at enrolment: age, gender, reasons for mechanical ventilation, and severity of illness status assessed using APACHE II. The doubleballoon catheter was filled with $1 \mathrm{ml}$ of air for the gastric balloon and $0.5 \mathrm{ml}$ of air for the oesophageal balloon.
Balloon position was checked using the occlusion test and the abdominal manoeuvre [16]. The physiological variables were displayed continuously on a computer screen. Oxygen saturation via a pulse oximeter $\left(\mathrm{SpO}_{2}\right)$, heart rate (HR), and respiratory rate (RR) were monitored using an ICU monitor.

A heated pneumotachograph (Fleisch no.2, Lausanne, Switzerland) connected to a differential pressure transducer (Validyne MP45, $80 \mathrm{cmH}_{2} \mathrm{O}$, Northridge, CA, USA) was placed between the mask and ventilator tubing to measure flow at the airway opening. Tidal volume was obtained by digital integration of the flow (Fig. 1). Airway pressure was measured from a side port between the pneumotachograph and face mask.

Transdiaphragmatic pressure (Pdi) was calculated electrically by subtracting the oesophageal pressure signal (Poes) from the gastric pressure (Pga) signal [16, 17]. The pressure-time product of the diaphragm was calculated per breath by integration of the transdiaphragmatic pressure signal per breath (PTPdi/b) and per minute (PTPdi/min). PTPdi/b was obtained by measuring the area under the Pdi signal from the onset of its positive deflection to its return to baseline. PTPdi/min was obtained by multiplying PTPdi/breath by the respiratory rate $[16,17]$.

Arterial blood gas values were measured (ABL 520 Radiometer, Copenhagen, Denmark) after each of the five study sessions in the patients who already had an arterial catheter. In the other patients, no blood samples were drawn.

The patients were asked to evaluate comfort during NIV and IPV using the following scale: 1 , severe discomfort; 2, discomfort; 3, acceptable level of comfort; 4, good level of comfort; 5 , very good level of comfort.

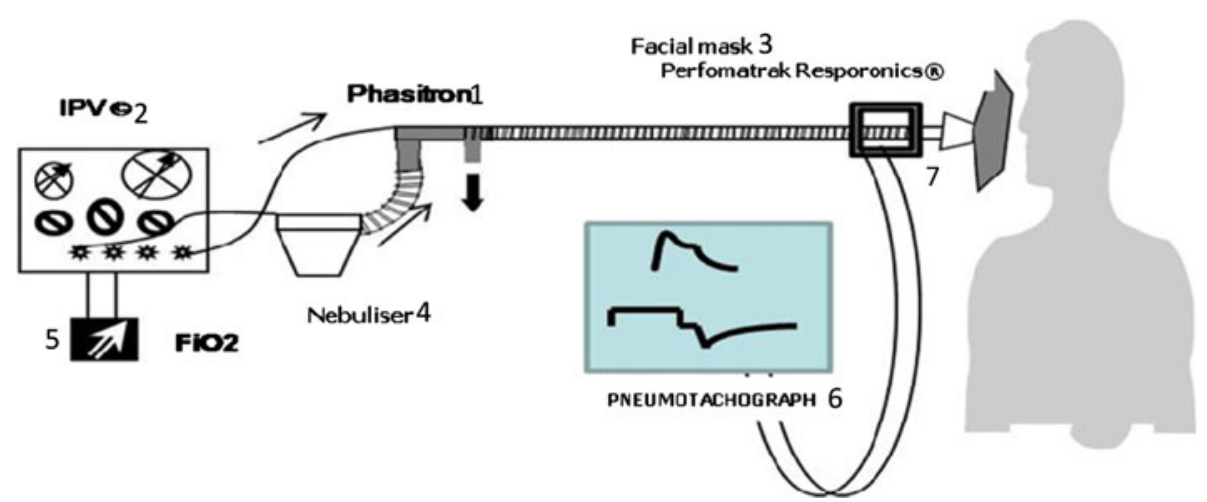

Fig. 1 Schematic representation of the circuit. Intrapulmonary percussive ventilation $(I P V)$ provides a pulsatile flow; the Phasi$\operatorname{tron}^{\circledR}(1)$ in the IPV uses a sliding flow based on the venturi effect. Gas from the nebuliser is dragged through the Phasitron ${ }^{\circledR}$. The circuit is a single line connected to the IPV device (2). The face mask (3) was adjusted to the patient. Humidification was provided by the nebuliser (4). Only two parameters were set, pressurisation frequency (250 cycles/min) and driving pressure (1.2 bar). The $\mathrm{FiO}_{2}$ was to obtain adequate oxygenation via the blender (5). Flow at the airway opening was measured using a heated pneumotachograph (6) and a differential pressure transducer (7) placed between the mask and the ventilator tubing. All parameters were recorded and analysed on a personal computer 


\section{Statistics}

Data are described as median and interquartile range [25th-75th percentiles]. Measurements were made at stability. The last $5 \mathrm{~min}$ of each measurement session was taken into account for the analysis. Owing to the small number of patients $(<30)$, we used non-parametric analysis of variance and two-by-two tests. When tested, the distribution was not normally distributed for several variables. We compared NIV, IPV, spontaneous breathing (SB), intermediate SB (ISB), and final SB (FSB) sessions with a Friedman (non-parametric) analysis of variance. When positive, we performed two-by-two comparisons between periods using the Wilcoxon test. We first checked that there was no difference for any comparison between the three spontaneous breathing periods. We then compared IPV or NIV to all SB periods. Data were analysed with SPSS16.0 for Windows statistical software (SPSS Inc., Chicago, IL, USA). To correct for multiple comparisons (Bonferroni correction), we considered a $p$ value equal to or smaller than 0.01 to indicate significance.

\section{Results}

Study population

We included 17 patients (Table 1). All patients tolerated the experimental procedure well. Eight patients received IPV first and nine received NIV first. Six patients had COPD and had mild respiratory acidosis after extubation.

Table 1 Characteristics of the 17 patients at enrolment

\begin{tabular}{ll}
\hline Variables & \\
\hline Age (years) & $73[58-75]$ \\
Gender (M/F) & $14 / 3$ \\
APACHE II at inclusion & $15[14-18]$ \\
$\mathrm{COPD}$ & $6 / 17(35 \%)$ \\
$\mathrm{RR}$ (breaths/min) & $25[19-28]$ \\
$\mathrm{HR}$ (beats/min) & $94[89-108]$ \\
$\mathrm{pH}$ & $7.38[7.37-7.40]$ \\
$\mathrm{PaCO}(\mathrm{mmHg})$ & $46[42-48]$ \\
$\mathrm{PaO}_{2} / \mathrm{FiO}(\mathrm{mmHg})$ & $266[204-282]$ \\
$\mathrm{Reason}_{2}$ for initiating mechanical & \\
ventilation $(n)$ & 3 \\
$\mathrm{COPD}$ exacerbation & 3 \\
Septic shock & 1 \\
Pneumonia & 8 \\
Heart failure & 2 \\
Others & \\
\hline
\end{tabular}

APACHE II Acute Physiology and Chronic Health Evaluation II, COPD chronic obstructive pulmonary disease, RR respiratory rate, HR heart rate

Values are medians [25th-75th percentiles]
The most frequent reason for intubation was heart failure. The APACHE II score was relatively high at inclusion, 15 [14-18].

\section{Tolerance}

Both NIV and IPV were well tolerated. None of the patients reported breathing difficulties with either modality. One patient complained that IPV was too noisy. The median comfort score was 3 for both IPV and NIV. One patient required re-intubation after $6 \mathrm{~h}$ for respiratory muscle weakness due to ICU-acquired paresis and difficulty clearing secretions.

\section{Effects on oxygenation and ventilation}

IPV and NIV caused significant reductions in median respiratory rate, from 23 [19-27] to 22 [17-24] breaths/ min for IPV and from 25 [19-28] to 20 [18-22] breaths/ min for NIV ( $p<0.01$ for both) (Fig. 2).

Arterial blood gas values were obtained in 13 patients. Neither IPV nor NIV significantly changed the $\mathrm{PaO}_{2} / \mathrm{FiO}_{2}$ ratio (see Fig. S2 in the ESM). Median $\mathrm{PaCO}_{2}$ decreased significantly with NIV (46 [42-48] vs. 41 [36-42] mmHg, $p<0.01)$, but did not change significantly with IPV (Fig. 3). Likewise, in the subgroup of hypercapnic patients with mild acidosis after extubation, IPV did not significantly reduce $\mathrm{PaCO}_{2}$.

\section{Respiratory rate over different measurement sessions}

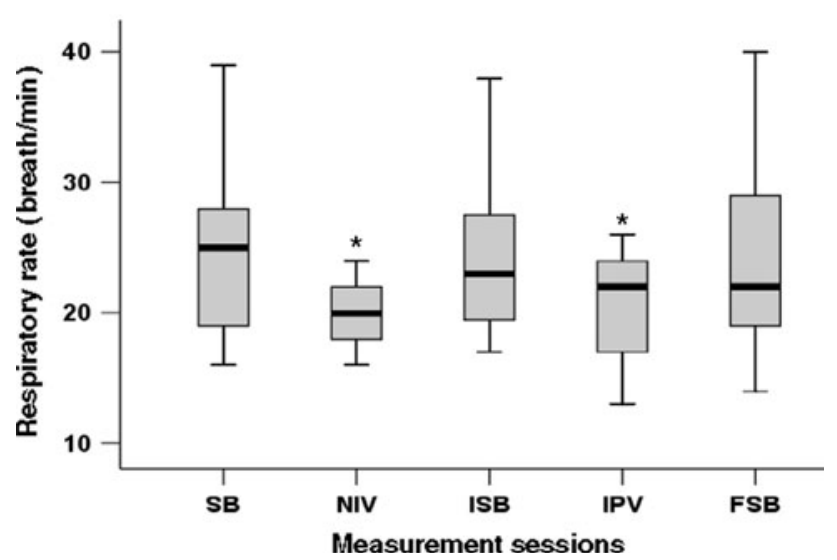

Fig. 2 Box plots summarising respiratory rate variation during different respiratory sessions. Box plots show median, interquartile range (25th-75th percentiles), and outliers (5th-95th percentiles) of respiratory rate in different ventilatory periods. $R R$ respiratory rate,

$S B$ spontaneous breathing, $I P V$ intrapulmonary percussive ventilation, ISB intermediate spontaneous breathing, $N I V$ non-invasive ventilation, $F S B$ final spontaneous breathing period. $* p<0.01$ versus SB (Wilcoxon test) 


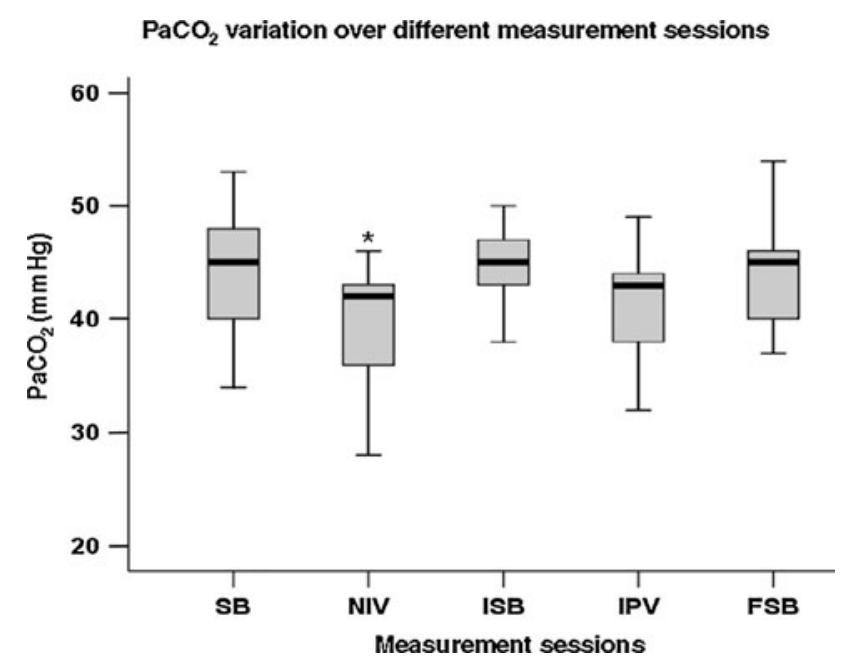

Fig. 3 Box plots showing changes in $\mathrm{PaCO}_{2}$ during the study measurement sessions in the 13 patients who underwent blood gas analysis. The plots show the median, interquartile range $(25 \mathrm{th}-75$ th percentiles), and outliers (5th-95th percentiles) of $\mathrm{PaCO}_{2}$ values in $\mathrm{mmHg}$. $S B$ spontaneous breathing, $I P V$ intrapulmonary percussive ventilation, $I S B$ intermediate spontaneous breathing session, NIV non-invasive ventilation, $F S B$ final spontaneous breathing session. ${ }^{*} p<0.01$ versus SB (Wilcoxon test)

Effects on diaphragmatic work

Significant decreases in Pdi, PTPdi/breath, and PTPdi/min occurred with both IPV and NIV (Fig. 4, Table 2). Median PTPdi/min decreased with NIV from 273 [212-397] to 176 [120-216] $\mathrm{cmH}_{2} \mathrm{O}$ s/min and with IPV from $264[190-300]$ to $192[152-221] \mathrm{cmH}_{2} \mathrm{O} \mathrm{s} / \mathrm{min}$ $(p<0.01)$. PTPdi/breath and PTPdi/min were thus significantly reduced, by about $35 \%$ with NIV and $20 \%$ with IPV; the difference between NIV and IPV was not significant $(p=0.15)$ (Fig. S3 in ESM).

\section{Discussion}

We found that IPV used for a short period unloaded the inspiratory muscles in patients at high risk for re-intubation. When superimposed over spontaneous breathing, IPV slightly changed the pattern of breathing and reduced the work of breathing but did not modify alveolar ventilation.

\section{Diaphragmatic work}

In this physiological study, NIV or IPV applied immediately after extubation significantly unloaded the diaphragm, by approximately $35 \%$ with NIV and $20 \%$ with IPV. To evaluate the respiratory muscle effort, we used PTPdi/min, which correlates with inspiratory muscle oxygen consumption [17]. Unloading was more pronounced with NIV than with IPV. NIV has been shown to both decrease the patient's respiratory muscle effort by providing adequate ventilatory support and increase alveolar ventilation [18-20]. The three periods of spontaneous breathing enabled the patients to return to their baseline
Fig. 4 Traces of a representative patient during spontaneous breathing $(S B)$, non-invasive ventilation (NIV), and intrapulmonary percussive ventilation $(I P V)$. The following were recorded: Flow; oesophageal pressure (Poes); airway pressure (Paw); gastric pressure $(P g a)$; and transdiaphragmatic pressure (Pdi)

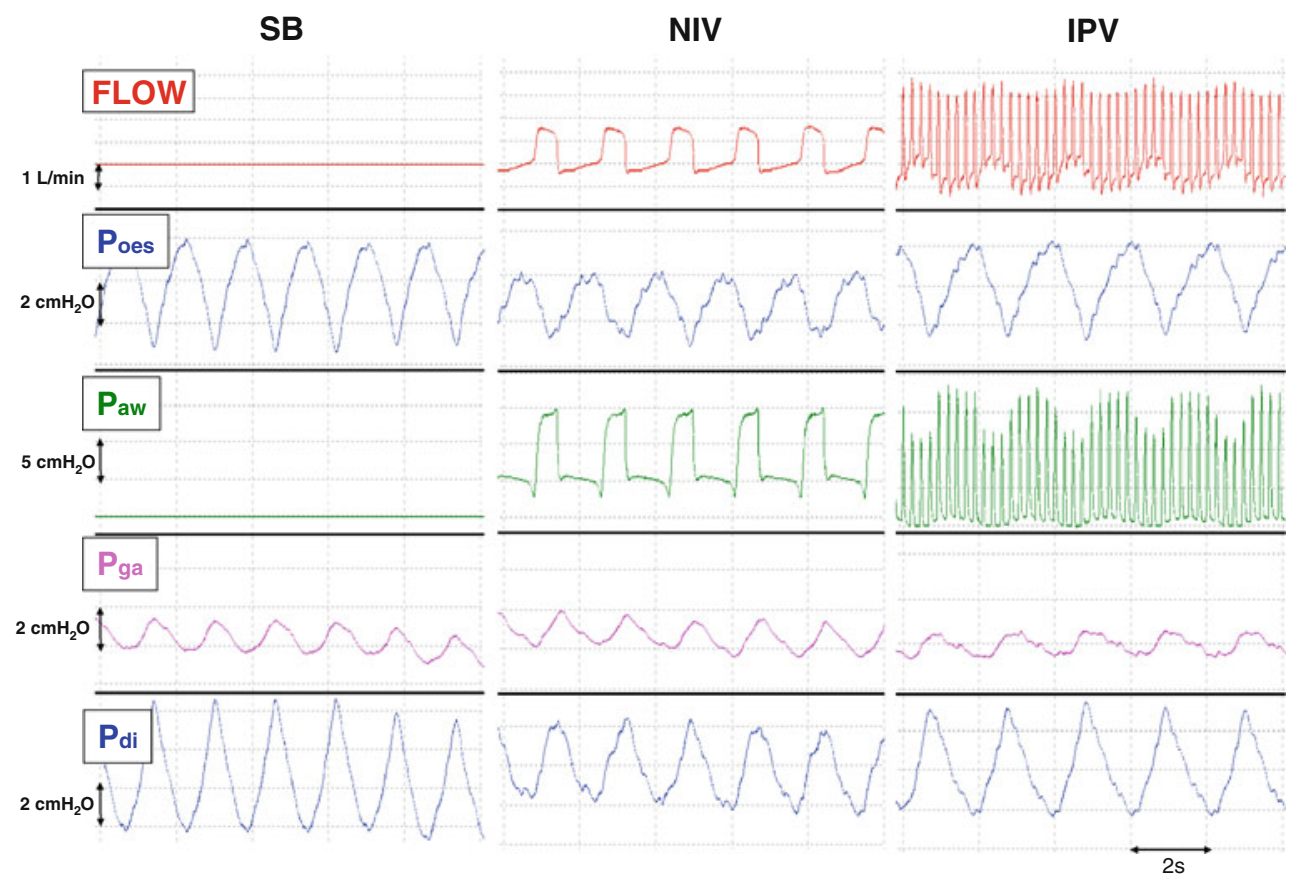


Table 2 Effects on diaphragmatic work

\begin{tabular}{llllll}
\hline & SB & NIV & Intermediate SB & IPV & Final SB \\
\hline Pdi $\left(\mathrm{cmH}_{2} \mathrm{O}\right)$ & $9[7-15]$ & $5[4-8]^{*}$ & $10[6-12]$ & $7[5-10]^{*}$ & $8[6-14]$ \\
PTPdi/breath $\left(\mathrm{cmH}_{2} \mathrm{O} \mathrm{s}\right)$ & $11[8-14]$ & $7[6-11]^{*}$ & $10[8-14]$ & $9[7-11]^{*}$ & $10[9-12]$ \\
PTPdi/min $\left(\mathrm{cmH}_{2} \mathrm{O} \mathrm{s} / \mathrm{min}\right)$ & $273[212-397]$ & $176[120-216]^{*}$ & $264[190-300]$ & $192[152-221]^{*}$ & $270[216-288]$ \\
\hline
\end{tabular}

Values are medians [25th-75th percentiles]

$* p<0.01$ versus (SB; Intermediate SB and Final SB) (Wilcoxon test)

level between the ventilatory support sessions, which avoided any bias caused by a ventilatory device effect.

The first physiological study of IPV was conducted by Nava et al. [13] and established that the application of IPV in 10 stable COPD patients was associated with a significant reduction in diaphragm energy expenditure (PTPdi/min and PTPdi/b) via a ventilatory effect. In addition, in this study of 10-min-long IPV sessions, 15 min of spontaneous breathing between sessions was sufficient to return the study parameters to the baseline values [13]. In our study, 20 min of spontaneous breathing was sufficient to return the parameters to baseline. The decrease in effort was significant compared to all spontaneous breathing periods.

Dellamonica et al. found an interesting physiological effect after a 30-min IPV session in the immediate postextubation period in patients with COPD [31]: work of breathing was not measured, but expiratory flow limitation and airway occlusion pressure after $0.1 \mathrm{~s}(\mathrm{P} 0.1)$ were both significantly improved. In our study, 20 min of IPV slightly but significantly reduced the work of breathing. This effect lasted only for as long as IPV was applied. However, it would be of interest to evaluate the effect of several IPV sessions or of longer IPV sessions.

\section{Respiratory rate and gas exchange}

We found that IPV or NIV induced significant changes in the breathing pattern, which were more marked with NIV. As previously reported, NIV was associated with a decrease in the respiratory rate, and with increases in the tidal volume and minute ventilation $[20,21]$. A recent review [20] found variations in the respiratory rate response to NIV: in most studies, mean respiratory rate decreased, on average by 6 breaths/min, whereas in a few studies it remained unchanged. Several studies described changes in breathing pattern induced by IPV [14, 22, 23]. In one study, 30 min of IPV after extubation significantly decreased the respiratory rate [22]. Conceivably, the rhythmic changes in airway pressure and vibrations of the intercostal muscles may stimulate the mechanoreceptors, inducing a reflex responsible for changes in breathing control [22]. This hypothesis needs to be confirmed.

Both NIV and IPV maintained adequate $\mathrm{PaO}_{2} / \mathrm{FiO}_{2}$ values, but only NIV significantly decreased $\mathrm{PaCO}_{2}$. The lack of an effect on oxygenation may be partly ascribable to insufficient statistical power, as only 13 patients underwent arterial blood gas measurement. Studies of NIV consistently showed either significant improvements or a trend toward improvements in oxygenation [13, 20, $24,25]$. NIV can enhance oxygenation and minute ventilation via two mechanisms, namely respiratory muscle unloading during inspiration and an increase in tidal volume associated with an increase in alveolar ventilation [21]. High-frequency percussive ventilation has been shown to significantly improve the $\mathrm{PaO}_{2} / \mathrm{FiO}_{2}$ ratio in several categories of patients, including burn patients [26], obese patients with compression atelectasis [27], patients with acute respiratory distress syndrome [9, 28], newborns [9], tracheotomised patients [29], and postoperative patients [30].

Several mechanisms may explain the effects of IPV. The first suggested benefit of IPV was a better clearance of excessive bronchial and peripheral secretions, reducing resistance and leading to enhanced ventilation [8, 10]. Two mechanisms may facilitate mucus clearance with high-frequency oscillation: an increased mucus-flow interaction leading to decrease in mucus viscoelasticity; second, the transient change in air flow with each highfrequency cycle could produce shearing at the air-mucus interface and provide a cough-like force to the mucus layer. An additional reflex effect of the high-frequency oscillation on respiratory centres through chest wall or airway receptors is another possible hypothesis that could play a role.

An internal PEEP effect is also possible [13, 14]. As Dellamonica et al. [31] point out, the level of PEEP induced by IPV is very dependent on respiratory mechanics and tidal volume (from 1.7 to $4.3 \mathrm{cmH}_{2} \mathrm{O}$ ), using the same setting as in our study $(1.2 \mathrm{bar}$ and 250-300 cycles/min). On the basis of these results, it is unlikely that intrinsic PEEP could have been higher than 4 or $5 \mathrm{cmH}_{2} \mathrm{O}$, the level used with NIV. In our study, the levels of intrinsic PEEP during the pressure-support period and IPV periods were $1.6 \mathrm{cmH}_{2} \mathrm{O}$ [1.1-2.2] during NIV and $2.5 \mathrm{cmH}_{2} \mathrm{O}$ [1.3-3.5] during IPV. This finding is compatible with the results of the bench study. In the post-extubation period, IPV has been shown to diminish the expiratory flow limitation and the airway occlusion pressure after $0.1 \mathrm{~s}$, indicating a decrease in the work of breathing [22]. These findings suggest that IPV may 
provide additional ventilation and generate internal endexpiratory pressure, two effects that may work together to decrease the work of breathing. A comparison with continuous positive airway pressure (CPAP) could also have been interesting.

IPV may thus constitute an alternative to NIV in this period of prevention of post-extubation respiratory distress.

\section{Limitations}

Comparisons of different ventilation modes must always be considered with caution, as a given mode may have different effects depending on the settings. We chose settings that have been found effective in decreasing the work of breathing [13]. A more detailed assessment of a dose-response effect of this technique could be of interest in the future. Adding IPV to conventional ventilation may also decrease the humidity of the delivered gases. The IPV device nebuliser does not provide adequate humidification [31, 32]. The Phasitron ${ }^{\circledR}$ increases gas flow, decreases gas temperature and, subsequently, lowers absolute humidity. The current connection circuit does not allow the connection of a heat and moisture exchanger. The use of IPV for longer periods would require prior improvements in the humidification system.

\section{Conclusions}

Prophylactic IPV sessions in a selected population at high risk for re-intubation can decrease the diaphragmatic energy expenditure. IPV used with these settings and in non-acidotic patients is less effective than NIV in improving alveolar ventilation. Nevertheless, IPV is a relatively simple system that is easy to tolerate, does not require a tight-fitting mask (which usually helps tolerance), and does not need synchronisation. IPV could therefore be interesting for relieving dyspnea and decreasing the work of breathing.

Acknowledgments We are grateful to International Medical Assistance by Percussionaire for lending us the device for the physiological study. We thank the physicians and nurses involved in this study, as well as the physiotherapists Emmanuelle Akachian, Frédérique Phillipe, and Julia Lefranc.

\section{References}

1. Epstein SK (2004) Extubation failure: an outcome to be avoided. Crit Care 8:310-312

2. Epstein SK, Ciubotaru RL (1998) Independent effects of etiology of failure and time to reintubation on outcome for patients failing extubation. Am J Respir Crit Care Med 158:489-493

3. Epstein SK, Ciubotaru RL, Wong JB (1997) Effect of failed extubation on the outcome of mechanical ventilation. Chest 112:186-192

4. (2001) International Consensus Conferences in Intensive Care Medicine: noninvasive positive pressure ventilation in acute Respiratory failure. Am J Respir Crit Care Med 163:283-291

5. Ferrer M, Valencia M, Nicolas JM, Bernadich O, Badia JR, Torres A (2006) Early noninvasive ventilation averts extubation failure in patients at risk: a randomized trial. Am J Respir Crit Care Med 173:164-170

6. Nava S, Gregoretti C, Fanfulla F, Squadrone E, Grassi M, Carlucci A, Beltrame F, Navalesi P (2005) Noninvasive ventilation to prevent respiratory failure after extubation in high-risk patients. Crit Care Med 33:2465-2470
7. Ferrer M, Sellares J, Valencia M, Carrillo A, Gonzalez G, Badia JR, Nicolas JM, Torres A (2009) Noninvasive ventilation after extubation in hypercapnic patients with chronic respiratory disorders: randomised controlled trial. Lancet 374:1082-1088

8. Branson RD (2007) Secretion management in the mechanically ventilated patient. Respir Care 52:1328-1342 discussion 1342-1327

9. Salim A, Martin M (2005) Highfrequency percussive ventilation. Crit Care Med 33:S241-S245

10. Toussaint M, De Win H, Steens M, Soudon P (2003) Effect of intrapulmonary percussive ventilation on mucus clearance in Duchenne muscular dystrophy patients: a preliminary report. Respir Care 48:940-947

11. Natale JE, Pfeifle J, Homnick DN (1994) Comparison of intrapulmonary percussive ventilation and chest physiotherapy. A pilot study in patients with cystic fibrosis. Chest 105:1789-1793

12. Deakins K, Chatburn RL (2002) A comparison of intrapulmonary percussive ventilation and conventional chest physiotherapy for the treatment of atelectasis in the pediatric patient. Respir Care 47:1162-1167
13. Nava S, Barbarito N, Piaggi G, De Mattia E, Cirio S (2006) Physiological response to intrapulmonary percussive ventilation in stable COPD patients. Respir Med 100:1526-1533

14. Vargas F, Bui HN, Boyer A, Salmi LR, Gbikpi-Benissan G, Guenard H, Gruson D, Hilbert G (2005) Intrapulmonary percussive ventilation in acute exacerbations of COPD patients with mild respiratory acidosis: a randomized controlled trial [ISRCTN17802078]. Crit Care 9:R382-R389

15. Knaus WA, Draper EA, Wagner DP, Zimmerman JE (1985) APACHE II: a severity of disease classification system. Crit Care Med 13:818

16. Diehl JL, Lofaso F, Deleuze P, Similowski T, Lemaire F, Brochard L (1994) Clinically relevant diaphragmatic dysfunction after cardiac operations. J Thoracic Cardiovasc Surg 107:487-498

17. Tobin MJ, Laghi F, Brochard L (2009) Role of the respiratory muscles in acute respiratory failure of COPD: lessons from weaning failure. J Appl Physiol 107:962-970

18. Brochard L (2002) Noninvasive ventilation for acute respiratory failure. Jama 288:932-935 
19. Brochard L, Harf A, Lorino H, Lemaire F (1989) Inspiratory pressure support prevents diaphragmatic fatigue during weaning from mechanical ventilation. Am Rev Respir Dis 139:513-521

20. Kallet RH, Diaz JV (2009) The physiologic effects of noninvasive ventilation. Respir Care 54:102-115

21. Brochard L, Isabey D, Piquet J, Amaro $\mathrm{P}$, Mancebo J, Messadi AA, BrunBuisson C, Rauss A, Lemaire F, Harf A (1990) Reversal of acute exacerbations of chronic obstructive lung disease by inspiratory assistance with a face mask. N Engl J Med 323:1523-1530

22. Vargas F, Boyer A, Bui HN, Guenard H, Gruson D, Hilbert G (2009) Effect of intrapulmonary percussive ventilation on expiratory flow limitation in chronic obstructive pulmonary disease patients. J Crit Care 24:212-219

23. Antonaglia V, Lucangelo U, Zin WA, Peratoner A, De Simoni L, Capitanio G, Pascotto S, Gullo A (2006) Intrapulmonary percussive ventilation improves the outcome of patients with acute exacerbation of chronic obstructive pulmonary disease using a helmet. Crit Care Med 34:2940-2945

24. Antonelli M, Conti G, Rocco M, Bufi M, De Blasi RA, Vivino G, Gasparetto A, Meduri GU (1998) A comparison of noninvasive positive-pressure ventilation and conventional mechanical ventilation in patients with acute respiratory failure. N Engl J Med 339:429-435
25. Brochard L, Mancebo J, Wysocki M, Lofaso F, Conti G, Rauss A, Simonneau G, Benito S, Gasparetto A, Lemaire F et al (1995) Noninvasive ventilation for acute exacerbations of chronic obstructive pulmonary disease. N Engl J Med 333:817-822

26. Reper P, Van Bos R, Van Loey K, Van Laeke P, Vanderkelen A (2003) High frequency percussive ventilation in burn patients: hemodynamics and gas exchange. Burns 29:603-608

27. Tsuruta R, Kasaoka S, Okabayashi K, Maekawa T (2006) Efficacy and safety of intrapulmonary percussive ventilation superimposed on conventional ventilation in obese patients with compression atelectasis. J Crit Care 21:328-332

28. Esan A, Hess DR, Raoof S, George L, Sessler CN (2010) Severe hypoxemic respiratory failure: part 1-ventilatory strategies. Chest 137:1203-1216

29. Clini EM, Antoni FD, Vitacca M, Crisafulli E, Paneroni M, Chezzi-Silva S, Moretti M, Trianni L, Fabbri LM (2006) Intrapulmonary percussive ventilation in tracheostomized patients: a randomized controlled trial. Intensive Care Med 32:1994-2001
30. Lucangelo U, Antonaglia V, Zin WA, Confalonieri M, Borelli M, Columban M, Cassio S, Batticci I, Ferluga M, Cortale M, Berlot G (2009) Highfrequency percussive ventilation improves perioperatively clinical evolution in pulmonary resection. Crit Care Med 37:1663-1669

31. Dellamonica J, Louis B, Lyazidi A, Vargas F, Brochard L (2008) Intrapulmonary percussive ventilation superimposed on conventional ventilation: bench study of humidity and ventilator behaviour. Intensive Care Med 34:2035-2043

32. Allan PF, Hollingsworth MJ, Maniere GC, Rakofsky AK, Chung KK, Naworol GA, Ward JA, Perello M, Morris MJ (2009) Airway humidification during high-frequency percussive ventilation. Respir Care $54: 350-358$ 